\title{
First record of egg sac predation of the fly Pseudogaurax cingulatus Sabrosky (Diptera, Chloropidae) upon spider Tetragnatha sp. (Araneae, Tetragnathidae) in northern Brazil
}

\author{
Paula Raile Riccardi' \& Diego Galvão de Pádua ${ }^{2}$
}

1 Universidade Federal do Rio de Janeiro (UFRJ), Museu Nacional (MN), Departamento de Entomologia. Rio de Janeiro, RJ, Brasil.
ORCID: http://orcid.org/0000-0003-4850-7524. E-mail: paularriccardi@gmail.com
2 Instituto Nacional de Pesquisas da Amazônia (INPA), Coordenação de Pesquisas em Entomologia (CPEN),

Programa de Pós-Graduação em Entomologia. Manaus, AM, Brasil. ORCID: http://orcid.org/0000-0001-5061-2978. E-mail: paduadg@gmail.com

\begin{abstract}
Pseudogaurax Malloch is a worldwide genus of Chloropidae with 33 species in the Neotropical region and 12 occurring in Brazil. The genus is well-known for the feeding habits of its larvae which attack egg masses and larvae of several arthropods, usually breeding in the egg sacs of spiders. In this study, we expanded the distribution of $P$. cingulatus to northern Brazil and recorded for the first time the species preying on Tetragnatha egg sacs. In addition, diagnosis, digital images and a distribution map are provided.
\end{abstract}

Key-Words. Biodiversity; Oscinellinae; Geographic distribution; Taxonomy; Neotropic.

\section{INTRODUCTION}

Pseudogaurax Malloch is a worldwide genus of Chloropidae well-known for the feeding habits of their larvae. They usually attack egg masses and larvae of several arthropods, usually breeding in egg sacs of spiders (Sabrosky, 1966; Melo \& Wheeler, 2009; González et al., 2016). Some species seem to be opportunists, utilizing a variety of hosts, however little is known about the life histories of several Pseudogaurax species (Barnes et al., 1992). There are 33 species of Pseudogaurax in the Neotropical region (Sabrosky \& Paganelli, 1984; Sabrosky, 1989; Barnes et al., 1992; Melo \&Wheeler, 2009). Of these, 12 species are recorded from Brazil (Riccardi, 2020), however, the knowledge of their distribution and biology are still scarce.

The species $P$. cingulatus Sabrosky occurs in the Brazilian territory with previous records to the states of São Paulo and Rio Grande do Sul (Sabrosky \& Paganelli, 1984) and, so far, this species was reared only from the araneid spider Metazygia unguiformis (= Alpaida veniliae (Keyserling)) (Sabrosky, 1966).

Here we provide a new record of occurrence for $P$. cingulatus including another spider host. Also, a diagnosis of $P$. cingulatus is given along with digital images and a distribution map.

\section{MATERIAL AND METHODS}

The study was conducted at the "Agrolucas" farm localized in the municipality Boa Vista, Roraima state, Brazil (Fig. 1). Spider egg sacs were collected during an expedition on August 2019. These samples were collected manually and each adult spider and respective egg sac was placed into a plastic tube (1.5 and $2.0 \mathrm{ml}$ ), transported to the rearing laboratory at Instituto Nacional de

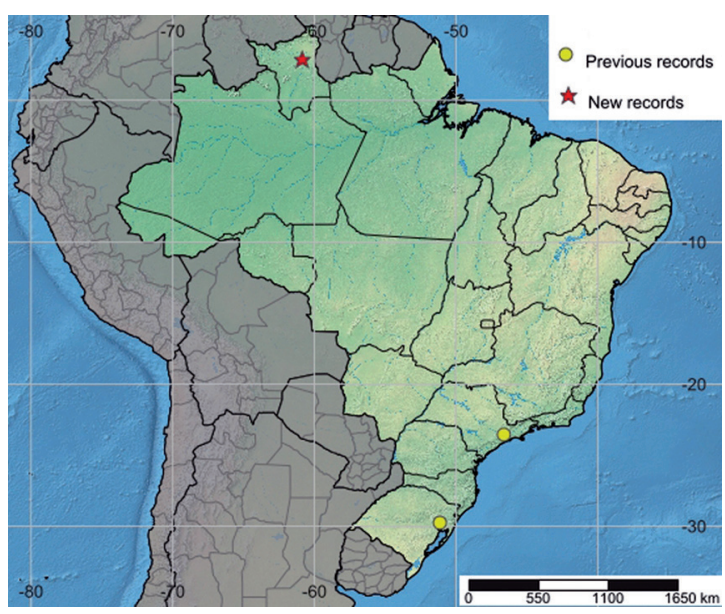

Figure 1. Geographic distribution of Pseudogaurax cingulatus Sabrosky (Diptera, Chloropidae) in Brazil. 
Pesquisas da Amazônia (INPA), where the egg sacs were kept until the emergence of the spiders or their predators/parasitoids. Among the material collected were egg sacs from Tetragnatha sp. $(n=3)$.

Voucher specimens of the spider (Figs. 2-4), its egg sacs (Fig. 5) and one Pseudogaurax cingulatus were deposited at the Invertebrate Collection of INPA and three
P. cingulatus vouchers were deposited at the Museu de Zoologia da Universidade de São Paulo (MZUSP). Additional specimens of $P$. cingulatus deposited at the MZUSP were examined. The identification of the emerged flies was made based on the key to species and original description of P. cingulatus of Sabrosky (1966), then compared with all more recent descriptions of
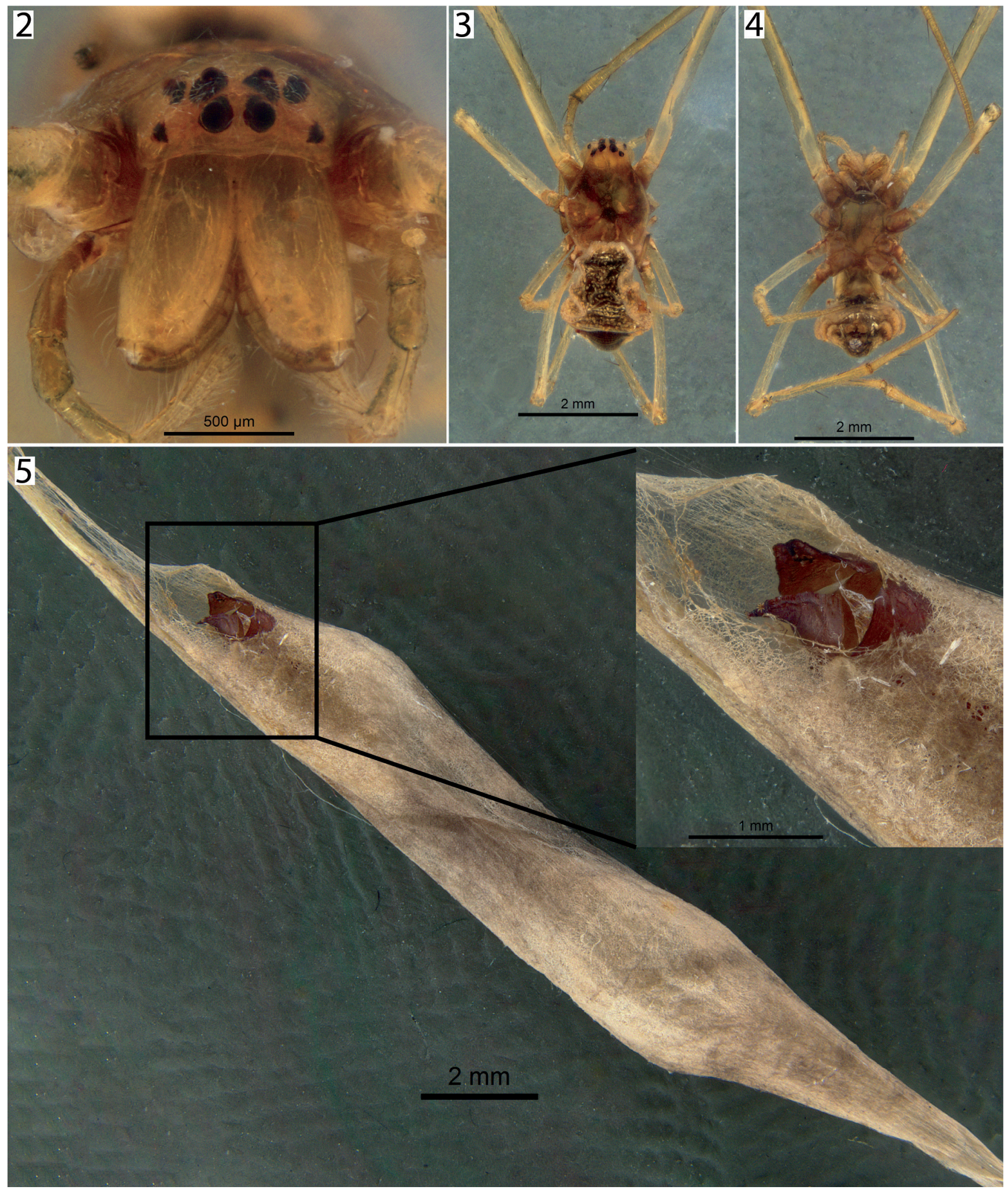

Figures 2-5. Tetragnatha sp. (Araneae, Tetragnathidae) (female). (2) adult face, frontal view. (3) adult habitus, dorsal view. (4) adult habitus, ventral view. (5) egg sac, rectangle enlarging and showing opening and apex of the puparium from which one of the flies emerged. 
the Neotropical Pseudogaurax species (Sabrosky, 1989; Barnes et al., 1992; Melo \& Wheeler, 2009).

Digital images of the chloropids and its puparium were taken using a stereomicroscope Leica M205C coupled to the software Las $\mathrm{X}$ and assembled in Helicon Focus 6 at the University of São Paulo and digital images of the spider and its egg sac were taken using a Leica DMC4500 digital camera attached to a Leica M205A stereomicroscope and combined by using the software Helicon Focus 5.3 Pro at INPA.

The protocol for preparing the female terminalia followed Riccardi et al. (2018). Pictures were treated with Adobe Photoshop CC and illustrations of the terminalia were vectorized with Adobe Illustrator CC. The morphological nomenclature followed Andersson (1977) and Cumming \& Wood (2017). The digital map was produced in the online website SimpleMappr (www.simplemappr. net).

\section{RESULTS}

\section{Pseudogaurax cingulatus Sabrosky, 1966 \\ (Figs. 6-10)}

Pseudogaurax cingulatus Sabrosky, 1966: 124. Type locality: Brazil, Rio Grande do Sul, São Leopoldo. Holotype male at Smithsonian Institution National Museum of Natural History, Washington DC, United States.

Diagnosis: Body pilosity pale. Head entirely yellow except the ocellar tubercle. Scutum yellow with a longitudinal black stripe; anepisternum with a black rounded spot (Fig. 6); scutellum slightly elongate; fore tibia and fore tarsus dark; hind tibia with a blackish stripe on the anterior $2 / 3$; tibial organ concolorous, oval, occupying half of the hind tibia length. Female terminalia telescopic; general shape and pilosity typical of Oscinellinae; $8^{\text {th }}$ ab-

\section{6}
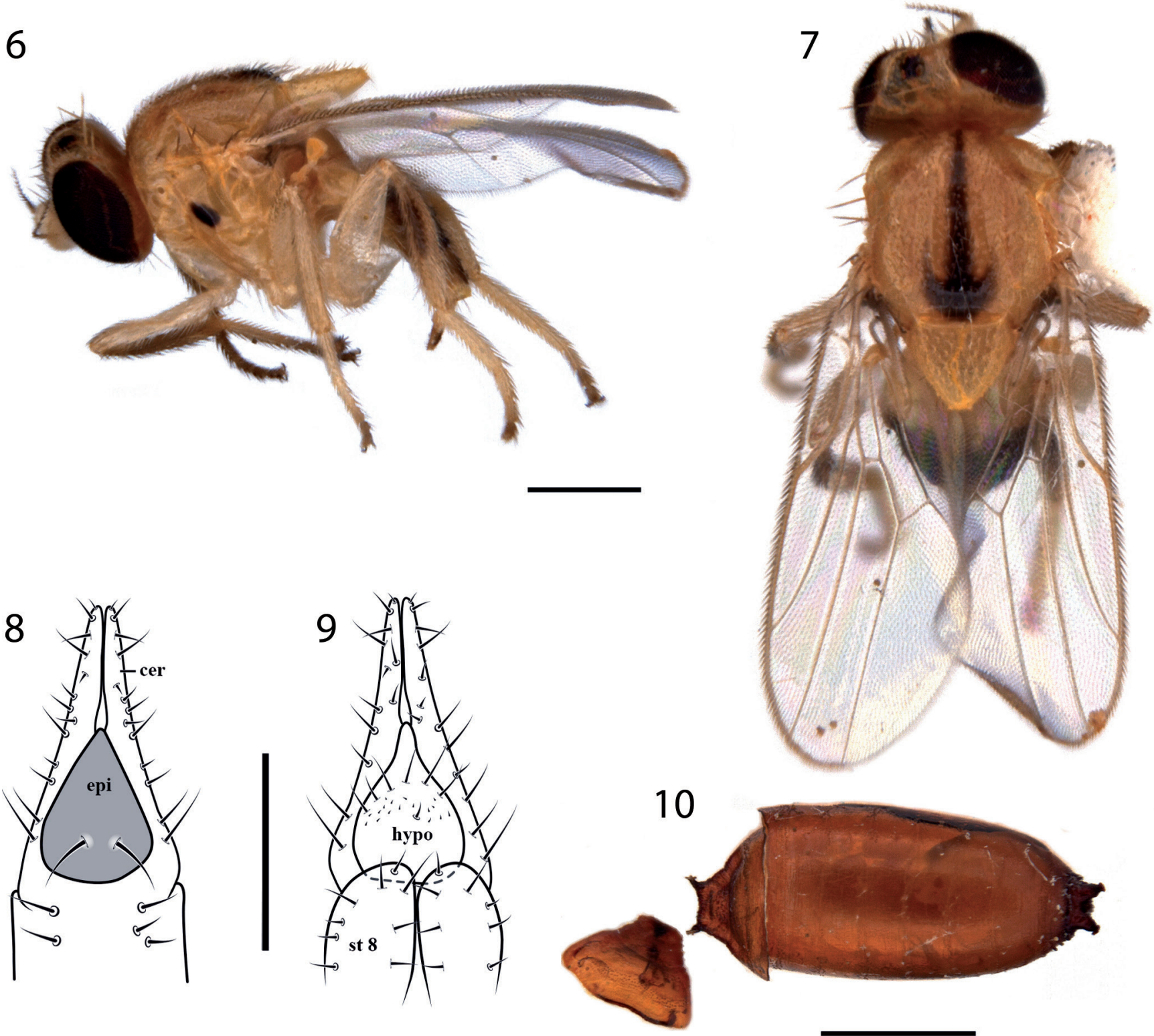

Figures 6-10. Pseudogaurax cingulatus Sabrosky (Diptera, Chloropidae) (female). (6) adult habitus (scale bar $=0.5 \mathrm{~mm}$ ). (7) adult, dorsal view. (8) female terminalia in dorsal view (scale bar $=0.1 \mathrm{~mm}$ ). (9) female terminalia in ventral view (scale bar $=0.1 \mathrm{~mm})$. (10) puparium in dorsal view; anterior left side (scale bar $=1 \mathrm{~mm}$ ). Abbreviations: cer, cercus; epi, epiproct; hypo, hypoproct; st 8, 8th abdominal sternite. 
dominal sternite divided in two lobes (Fig. 9); epiproct black with a pair of setae (Fig. 8); hypoproct pilose with microtrichiae mesally (Fig. 9); cercus narrow with the apex acute. Puparium typical of Chloropidae; anterior spiracle with four small lobes (Fig. 10).

Remarks: The specimens from Fazenda Agrolucas differ from the type material only in the scutum longitudinal stripe. Sabrosky's (1966) illustration of $P$. cingulatus (Fig. 14, p. 123) shows a scutal longitudinal stripe thin anteriorly and slightly wider posteriorly. However, the specimen from Fazenda Agrolucas exhibits an anchor-like mark posteriorly (Fig. 7) which is considered here an intraspecific variation. On the other hand, the additional specimens examined from Ilha de Maracá have the scutal stripe as the type of $P$. cingulatus, but the dark marks on the legs are faded. Pseudogaurax nigrolineatus (Enderlein) is another Brazilian species which has a scutum similar to $P$. cingulatus, but the absence of dark spots on pleuron and legs completely yellow are features restricted to the former species (Sabrosky, 1966). Unfortunately, no information on the male terminalia of $P$. cingulatus is available. This organ could improve the species identification and help confirm the specimens identity.

Material examined: 4 우 from BRAZIL, Roraima, Fazenda Agrolucas, $02^{\circ} 52^{\prime} 29.7^{\prime \prime} \mathrm{N}, 60^{\circ} 51^{\prime} 48.9^{\prime \prime} \mathrm{W}$, egg sacs collected 22.viii.2019 and specimen emerged on 04.ix.2019, N. Hamada leg. [MZUSP and INPA]. 2 \%o from BRAZIL, Roraima, Ilha de Maracá, Estação Ecológica de Maracá, $03^{\circ} 22.623^{\prime} \mathrm{N}, 61^{\circ} 26.136^{\prime} \mathrm{W}, 101 \mathrm{~m}$, Malaise trap ponto 5, trilha Santa Rosa, 20.xi-05.xii.2015, Biffi, Falaschi, Marinho \& Riccardi leg. [MZUSP]; 1 \% same data except 29.ix-14.x.2015 [MZUSP].

Biological note: Egg sac predator of the spider Metazygia unguiformis (= Alpaida veniliae (Keyserling)) (Araneidae) (Sabrosky, 1966) and Tetragnatha sp. (Tetragnathidae) (Figs. 1-4).

Distribution: Brazil (Roraima, São Paulo, Rio Grande do Sul) (Fig. 1).

\section{DISCUSSION}

The Tetragnatha sp. egg sacs $(n=3)$ were collected on August 22, 2019 and 13 days after (September 4, 2019) four Pseudogaurax cingulatus specimens emerged. After emergency of the flies, four juvenile spiders emerged showing that $P$. cingulatus predation were not on $100 \%$ of the spider eggs. Barnes et al. (1992) observed that the predation of $P$. higginsi Sabrosky and P. mexoculatus Sabrosky in many Trichonephila clavipes (Linnaeus) egg sacs was also not total. The predatory behavior of Pseudogaurax larvae is unlike other insect groups, such as the wasp Tromatobia sp. (Ichneumonidae, Pimplinae) its larvae fully prey the egg sac of Araneus omnicolor (Keyserling) (Sobczak et al., 2012).

Pseudogaurax larvae have been recorded preying egg sacs of the Araneidae, Tetragnathidae and
Theridiidae spiders (summarized in Barnes et al., 1992). Pseudogaurax cingulatus larvae is reared from egg sac of Metazygia unguiformis (= Alpaida veniliae (Keyserling)) (Araneidae) (Sabrosky, 1966) and now recorded emerging from Tetragnatha sp. (Tetragnathidae) egg sac. In Tetragnathidae, only egg sac of an unidentified species of Tetragnatha in Panamá has been preyed by P. silbergliedi Sabrosky (Sabrosky, 1989), and now P. cingulatus is recorded.

The geographic distribution of the Brazilian Pseudogaurax species is concentrated in the south-central region (states of Mato Grosso do Sul, Rio de Janeiro, São Paulo, Paraná, Santa Catarina and Rio Grande do Sul), except for two species - P. souzalopesi Sabrosky and P. trilineatus (Duda) - recorded in the northern region (states of Pará and Roraima respectively) (Rafael, 1991; Riccardi, 2020). However, the biased distribution of Pseudogaurax is due to the lack of studies of the chloropid diversity in northern and central Brazil. Our study, besides representing the third formal record of a Pseudogaurax species for the northern region, also reveal another host of $P$. cingulatus and some morphological variation within the species.

\section{ACKNOWLEDGEMENTS}

We grateful to Dr Antônio Brescovit for the identification of Tetragnatha sp. The material was collected with the expedition organized by $\mathrm{Dr}$ Neusa Hamada (SISBIO license № 49055-2), sponsored by CNPq (proc. 307849/2014-7). To the Invertebrate Collection of INPA for the possibility to use the layer-photo equipment. PRR benefits from the financial support of a CNPq Protax II grant (88887.176040/2018-00), and DGP from the Coordenação de Aperfeiçoamento de Pessoal de Nível Superior - Brasil (CAPES), Finance Code 001.

\section{AUTHORS' CONTRIBUTIONS}

PRR: photographed and identified the fly specimens. DGP: reared the spider egg sac and produced the spider pictures and the map. Both authors wrote the manuscript and discussed the results.

\section{REFERENCES}

Andersson, H. 1977. Taxonomic and phylogenetic studies on Chloropidae (Diptera) with special reference to Old World genera. Entomologica Scandinavica, 8: 5-199.

Barnes, J.K.; Higgins, L.E. \& Sabrosky, C.W. 1992. Life histories of Pseudogaurax species (Diptera: Chloropidae), descriptions of two new species, and ecology of Nephila clavipes (Linnaeus) (Araneae: Tetragnathidae) egg predation. Journal of Natural History, 26(4): 823-834.

Cumming, J.M. \& Wood, D.M. 2017. Adult morphology and terminology. In: Kirk-Spriggs, A.H. \& Sinclair, B.J. (Eds.). Manual of Afrotropical Diptera. Volume 1. Suricata 4. Pretoria, South African National Biodiversity Institute. Cap. 3, p. 89-133. 
González, C.T.; Wcislo, W.T.; Cambra, R.; Wheeler, T.A. \& Fernández-Marin, H. 2016. A new ectoparasitoid species of Pseudogaurax Malloch, 1915 (Diptera: Chloropidae), attacking the fungus-growing ant, Apterostigma dentigerum Wheeler, 1925 (Hymenoptera: Formicidae). Annals of the Entomological Society of America, 109(4): 1-7.

Melo, A.S. \& Wheeler, T.A. 2009. A new species of Pseudogaurax Malloch (Diptera: Chloropidae) reared from dobsonfly egg-masses (Megaloptera: Corydalidae) in Brazil. Zootaxa, 1972: 53-58.

Rafael, J.A. 1991. Insetos coletados durante o Projeto Maracá, Roraima, Brazil: lista complementar. Acta Amazonica, 21: 325-336 [Portuguese]. DOI

Riccardi, P.R. 2020. Chloropidae. In: Catálogo da Fauna do Brasil. PNUD. Available: http://fauna.jbrj.gov.br/fauna/faunadobrasil/140377. Access: 13/04/2020.

Riccardi, P.R.; Bazyar, Z. \& Lamas, C.E. 2018. New genus of the subfamily Oscinellinae from Brazil (Diptera: Chloropidae). Zootaxa, 4438(2): 394-400.
Sabrosky, C.W. 1966. Three new Brazilian species of Pseudogaurax with a synopsis of the genus in the western hemisphere (Diptera, Chloropidae). Papéis Avulsos do Departamento de Zoologia, Secretaria da Agricultura, São Paulo, 19(9): 117-127.

Sabrosky, C.W. 1989. New synonymy and new species in neotropical Chloropidae (Diptera). Memórias do Instituto Oswaldo Cruz, 84(4): 463-465.

Sabrosky, C.W. \& Paganelli, C.H. 1984. 81. Family Chloropidae. In: Papavero, N. A catalogue of the Diptera of the Americas south of the United States. São Paulo, Museu de Zoológia, Universidade de São Paulo. 63p.

Sobczak, J.F.; Loffredo, A.P.S. \& Sobczak, J.C.M.S.M. 2012. First record of egg sac predation of the wasp Tromatobia sp. Förster, 1869 (Hymenoptera: Ichneumonidae) upon Araneus omnicolor (Keyserling, 1893) (Araneae: Araneidae). Revista Ibérica de Aracnología, 20: 113-115. 